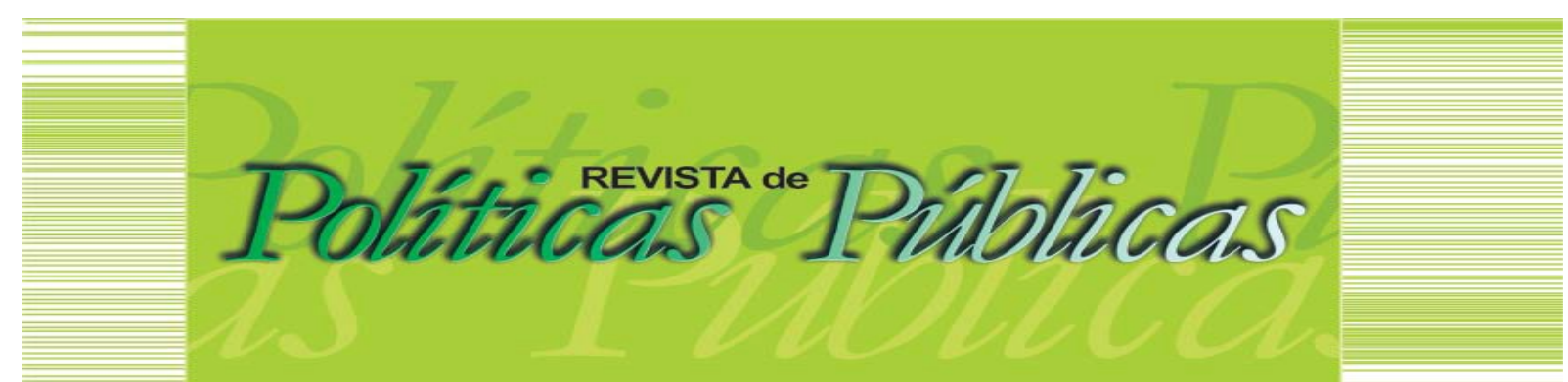

\title{
PENSANDO AS RELAÇÕES ÉTNICO-RACIAIS NO CONTEXTO LATINO-AMERICANO DEPENDENTE: uma questão contemporânea para o Serviço Social
}

Mirele Hashimoto Siqueira1

\section{Resumo}

O presente artigo tem como objetivo refletir sobre as relações étnico-raciais no contexto da realidade latino-americana dependente, buscando aferir de que maneira o traço histórico da dependência intensifica a questão racial. Partindo do pressuposto de que a América Latina está inserida numa posição periférica na divisão internacional do trabalho, os países deste continente estabelecem um intercâmbio desigual com os países do centro, adotando um modelo de desenvolvimento para fora e, portanto, externo. Nesta perspectiva, através de uma pesquisa bibliográfica, compreende que a questão racial assume na particularidade do continente latinoamericanoum caráter regressivo, visto que é acentuada pela hierarquização dos grupos étnico-raciais, pela superexploração da força de trabalho da região, servindo de instrumento para justificar a dominação capitalista que se infiltra em escala global.

Palavras-chave: Relações étnico-raciais. América Latina. Dependência. Serviço Social.

\section{THINKING ETHNIC-RACIAL RELATIONSHIPS IN THE DEPENDENT LATIN AMERICAN CONTEXT: a contemporary issue for Social Work}

\section{Abstract}

This article aims to reflect on ethnic-racial relations in the context of dependent Latin American reality, seeking to assess how the historical feature of dependence intensifies the racial issue. Based on the assumption that Latin America is inserted in a peripheral position in the international division of labor, the countries of this continent establish an unequal exchange with the countries of the center, adopting an outward and, therefore, external development model. In this perspective, through a bibliographic search, it is understood that the racial issue takes on the particularity of the Latin American continent a regressive character, since the hierarchy of ethnic-racial groups, accentuates it by the overexploitation of the region's workforce, serving as an instrument to justify the capitalist domination that infiltrates on a global scale.

Keywords: Ethnic-racial Relations. Latin America. Dependency.Social Work

Artigo recebido em: 29/05/2021 Aprovado em: 20/11/2021 DOI: http://dx.doi.org/10.18764/2178-2865.v25n2p687-700

\footnotetext{
1 Assistente Social. Doutoranda do Programa de Pós-Graduação em Serviço Social da Universidade Federal de Santa Catarina (UFSC). Bolsista da Coordenação de Aperfeiçoamento de Pessoal de Nível Superior (CAPES). Docente colaboradora da Universidade Estadual do Oeste do Paraná (UNIOESTE). E-mail: mirelehashimoto@hotmail.com
} 


\section{INTRODUÇÃO}

Considerando o conjunto complexo de determinações que atravessam o exercício profissional do/a Assistente Social e, particularmente, a realidade latino-americana dos tempos presentes, que não exige senão capacidade de reflexão analítica para transcender a pura aparência fenomênica da questão, coloca-se ao Serviço Social a questão das relações étnico-raciais; da questão racial e, mais: a questão do enfrentamento ao racismo e, portanto, das lutas antirracistas.

Afora isto, se o situarmos em um tempo e espaço específicos - a realidade latino-americana dos dias atuais - este tema adquire ainda maior complexidade: a dependência que invade as fronteiras de nossos paises traz consequências imensuráveis que superexplora os trabalhadores/as do continente, exclui os grupos étnicos minoritários e abandona um significativo contingente em situação de extrema vulnerabilidade social e verdadeiro estado de miserabilidade generalizada.

Por isso, refletir sobre as relações étnico-raciais no contexto da realidade latino-americana, implica em resgatar, sobretudo, as relações de dependência que tais países estabeleceram - e ainda estabelecem - desde sua "colonização". É a partir daí que podemos indagar sobre a relação "racismodependência", "dominação-superexploração" ou "imperialismo-neocolonialismo", de tal modo que estabelecemos como "questões norteadoras" para a presente reflexão os seguintes núcleos: Como se configuram as relações étnico-raciais no contexto latino-americano? Como o traço característico da dependência deste continente particulariza o racismo e/ou as relações étnico-raciais que aqui se estabelecem? Como superar o racismo histórico do continente e, por conseguinte, estabelecer novas relações étnico-raciais para buscar um novo horizonte livre para a América Latina?

Como tema que atravessa diretamente as demandas postas ao Serviço Social e a necessidade de compreendê-la e interpretá-la criticamente, a questão das relações étnico-raciais adquire relevância na medida em que deve estar conectada com o horizonte da luta antirracista que, por sua vez, não é senão, como veremos, a luta anticapitalista. Sem perder de vista a dimensão da exploração da "forma valor" a que se estrutura o modo de produção capitalista e o fermento ocasionado pela luta de classes, o Serviço Social é profissão que se relaciona diariamente com o contingente populacional segregado, superexplorado e ceifado em suas múltiplas determinações, ou seja, ausentes de condições mínimas para a reproduçãodas próprias necessidades do estômago e da fantasia. Este contingente, identificado nos grupos étnico-raciais, nos negros, nas mulheres, nos indígenas, é impactado na América Latina, sempre duplamente: 1) por se constituir num grupo segregado e; 2) inserido majoritariamente numa condição de superexploração da força de trabalho de um continente dependente.

Nesse sentido, nossa hipótese se centra na indissociabilidade da dependência e intensificação das relações étnico-raciais que adquirem aqui um caráter regressivo, porque aberto de preconceito, de 
discriminação e de uma cultura que segrega os grupos minoritários, ao passo de sua superexploração histórica. No mundo latino-americano neocolonizado, reforça-se a herança histórica da opressão e da submissão de tais grupos que servem ainda de amarra para a riqueza dos países cêntricos europeus ou colonos.

Assim é que o presente trabalho está organizado em dois subitens. 0 primeiro deles terá como objetivo apresentar a discussão da situação de dependência histórica latino-americana. Apresentando-a como uma parte constitutiva da dinâmica capitalista, a produção da dependência e, por conseguinte, do subdesenvolvimento da região, é a face oposta da Modernidade, muitas vezes ignorada e ocultada. Os países dependentes, participando de uma lógica na divisão internacional do trabalho, o fazem em uma posição periférica: estão aos caprichos e ao acúmulo de riquezas dos países cêntricos, reforçando o passo de sua economia exportadora e voltada para o exterior.

É, pois, a partir desta caracterização dos países dependentes e, em geral, da América Latina, que o segundo subitem situará a questão da configuração das relações étnico-raciais no contexto da periferia. Ora, em um continente cujo traço histórico da dependência é preservado e reproduzido, as relações étnicoraciais tendem a ser ainda mais intensificadas. A questão racial permanece ainda hoje reiterando, bem como refletindo as formas de sociabilidade vivenciadas, as relações de forças sociais que se estabelecem e as (in)tolerâncias reproduzidas e ditadas a partir do tipo de sociedade em que se insere.

Nesse sentido é que, buscando compreender como a questão étnica se desloca para a questão da raça, e assim se produz o racismo e as relações raciais que se estabelecem, situar este fenômeno na realidade latino-americana é ainda mais urgente e necessário, haja vista que a América Latina não só reproduz a lógica da hierarquização dos grupos étnico-raciais e adota um modelo étnico-racial ideal, mas está ao julgo do caráter racista do próprio modo de produção capitalista: um caráter que lhe é inerente porque serve para justificar o direito à dominação de algumas nações sob outras; de alguns povos sob outros.

\section{POR UM TEMPO E UM RITMO PRÓPRIO PARA A AMÉRICA LATINA: de fato, uma modernidade?}

Se a Modernidade, como historicamente é concebida, representa a entrada do mundo na era da razão e, por conseguinte, supera a imaturidade com o desenvolvimento das ciências exatas, físicas e matemáticas, ademais do desenvolvimento da concepção antropocêntrica e, portanto, racional, do mundo e do homem, é também consenso que a llustração, a Reforma e a Revolução Francesa coroam este processo histórico, inaugurando a era Moderna.

Para Dussel (2005), no entanto, esta concepção de Modernidade é muito limitada, exatamente porque é a representação apenas de um tempo, ritmo e espaço específicos, quer dizer: aquele tempo, ritmo e espaço da Europa. Considerar a Modernidade pelo processo clássico de transição histórica dos países 
centrais é excluir o tempo e ritmo próprio dos demais países e continentes, atribuindo a Europa o "ideal" a ser seguido. Esta concepção de Modernidade é, assim, eurocêntrica, haja vista que afora de considerá-la como modelo, impõe sua reprodução na periferia, sendo esta considerada como bárbara e atrasada, hierarquizando as culturas.

Assim, neste modelo, a Europa é o "centro", berço da civilização, donde se desenvolve todas as demais culturas a partir de seu entorno. É este modelo eurocêntrico de Modernidade que reproduz, como indica Dussel (2005), um etnocentrismo europeu. O que esta concepção exclui é precisamente o outro lado da Modernidade: o lado excluído, atrasado, explorado. A visão clássica eurocêntrica toma a Europa como 0 centro da história mundial, desconsiderando a sua face dominada e combatida, isto é, a cultura própria da periferia.

A América Latina pode ser exatamente identificada como o outro lado da Modernidade; é a periferia que, como tal, deve adotar o modelo ideal eurocêntrico ditado se quiser participar da lógica moderna. Em nome desta suposta "Modernidade" e do modelo europeu que promete uma pretensa elevação dos "povos bárbaros e primitivos" a povos civilizados, justifica-se o uso da violência para desenvolvê-los. É assim que, no mundo periférico, encontramos o "[...] o índio sacrificado, o negro escravizado, a mulher oprimida, a criança e a cultura popular alienadas, etc" (DUSSEL, 2005, p. 31). A América Latina é, pois, a vítima da Modernidade, alvo da própria irracionalidade dita "moderna".

Assim como Dussel (2005) reclama, é necessário desvelar o mito do Moderno, dado que ele não pode ser considerado apenas por uma visão regional, mas antes transmutar-se para uma visão mundial, em que o outro lado da Modernidade seja incluído, de fato, em seu processo. É necessário e urgente deslocar a visão eurocêntrica para uma visão global de mundo que respeite as mais distintas particularidades e tempos e ritmos dos continentes.

É por este ponto de partida, reivindicando uma história própria para a América Latina - uma história contada a partir de sua perspectiva - que se pode iniciar uma análise sobre sua dependência histórica. Ora, se Dussel já advertiu que a periferia se desenvolveu como uma espécie de apêndice da Europa, a América Latina também só participada era Moderna como subserviente aos desígnios do países centrais e europeus.

O mundo "subdesenvolvido", a que a América Latina pertence, se desenvolveu, como indica Florestan Fernandes (2008), a partir da expansão do mundo ocidental. Na particularidade brasileira, os portugueses, no processo de colonização, realizaram uma verdadeira simbiose entre expropriação colonial, trabalho escravo e plantação: o escravismo praticado em nome da "civilização" se planteou no país visando o sustento e a riqueza dos países europeus, em particular, da metrópole.

Mesmo com a constituição do Estado independente no Brasil não houve alterações profundas na organização econômica e política da sociedade. Os traços coloniais não foram rompidos e a relação de 


\title{
PENSANDO AS RELAÇÕES ÉTNICO-RACIAIS NO CONTEXTO LATINO-AMERICANO DEPENDENTE: uma questão contemporânea para o Serviço Social
}

dependência não foi cessada: se a metrópole portuguesa sucateava as matérias-primas da colônia e expropriava as suas riquezas a partir da própria força de trabalho escravizada, o advento do ideário liberal permaneceu a reiterar e, mesmo, atualizar as formas de espoliação latino-americana sob a coroa da Inglaterra, berço da Revolução Industrial (FERNANDES, 2008).

\begin{abstract}
A revolução industrial [...] corresponde na América Latina à independência política que, conquistada nas primeiras décadas do século 19 , fará surgir, com base na estrutura demográfica e administrativa construída durante a Colônia, um conjunto de países que passam a girar em torno da Inglaterra. Os fluxos de mercadorias e, posteriormente, de capitais têm nesta seu ponto de entroncamento: ignorando uns aos outros, os novos países se articularão diretamente com a metrópole inglesa e, em função dos requerimentos desta, começarão a produzir e a exportar bens primários, em troca de manufaturas de consumo e - quando a exportação supera as importações - de dívidas (MARINI, 1990, não paginado).
\end{abstract}

É assim que, de acordo com Florestan (2008), o colonialismo é atualizado e reforçado por meio da predominância na América Latina de um neocolonialismo pós-independência política. O neocolonialismo expressa, portanto, um processo contraditório: a indissociabilidade de países que se emanciparam politicamente, mas que permanecem colonialmente dependentes. Por esse motivo é que o imperialismo é a manifestação de uma herança colonial não rompida, mas semeada e transmutada na sua forma neocolonial, haja vista que a América Latina permanece a se situar como o incremento do excedente econômico dos países capitalistas mais avançados. Se ambos participam hoje do círculo civilizatório, o fazem em posições bastante distintas: os países subdesenvolvidos, quanto mais se expandem, mais se tornam dependentes (FERNANDES, 2008).

É claro que, como assinala Marini (1990), há uma diferença substancial entre a situação de dependência colonial e a situação de dependência. Embora haja uma continuidade entre ambas, já que permanecem a criar uma condição de submissão entre as nações, a situação de dependência é marcada pelo reforço do modo de produção capitalista e a participação efetiva da América Latina no contexto da divisão internacional do trabalho. Esta participação é, certa e diretamente, geradora da dependência e reforça a mesma condição de submissão colonial, mas está, agora, para fortalecer a grande indústria capitalista, sobretudo, a partir do século XIX.

Disso resulta o fato de que foi, certamente, aquela expansão do mundo ocidental, que produziu na particularidade brasileira e, em geral, também na latino-americana, uma economia voltada para a exportação, herança do período colonial precedente, mas que também se atualiza com o imperialismo, reclamando a predominância de um neocolonialismo, cujo traço histórico da dependência é reforçado. É assim que, a participação dessas economias dependentes na economia mundial se dá hoje, em sua mesma proporção, de maneira periférica, já que se volta para senvir não ao interior nacional, mas ao exterior, incrementando o ciclo do capital externo (FERNANDES, 2008). 
É finalmente Marini (1992) quem também assinala a importância de desvelar o tempo e ritmo próprio da América Latina, dado que o capitalismo não se desenvolve de forma homogênea em todos os espaços e regiões. Enquanto as revoluções burguesas clássicas dos países europeus disputavam 0 desenvolvimento de suas economias avançadas, no outro polo, criavam-se os laços de dependências e, por conseguinte, os vínculos coloniais, que submeteriam ad aternum alguns países em relação aos outros.

Nesse sentido, se a América Latina haveria de estar submetida aos desígnios das metrópoles no processo de colonização, o traço submisso e dependente se fortalece com a posição da Inglaterra no século XVIII, ao tornar-se potência econômica industrial, e transmuta-se, hoje, para a dependência que estabelece em relação ao poderio mundial norte-americano.

Conforme Marini (1992), o fim da Segunda Guerra Mundial é que reiterou o lugar reservado para a América Latina: uma posição dependente e inferior na divisão internacional do trabalho que fortalece 0 histórico modelo exportador, sustentado na superexploração do trabalho interno, servindo de complemento para a produção dos grandes centros. Isso porque o imperialismo - fase superior do capitalismo - e a partilha do mundo entre as grandes potências, reforçaram os vínculos coloniais, mas, agora, sob a égide norteamericana.

O pós-segunda Guerra Mundial evidencia, portanto, questões diversas no âmbito dos países avançados e dependentes. Para os primeiros, assiste-se um intenso incremento no desenvolvimento das pesquisas e na área do saber, produzindo alta tecnologia em seus territórios. Tudo isso incrementa um processo que Marini (1992) denomina de transição da economia mundial a uma etapa superior que luta por mercados. Já para os segundos, forçados a entrarem nesta disputa dos países avançados, participam da transição da economia mundial na medida em que, endividados pelos juros da dívida externa e pela própria dívida externa, acentuada principalmente no período das ditaduras militares no território latino-americano, devem acatar e aderir os programas de estabilização propostos a fim de gerar excedentes exportáveis, adquirir os bens de alta tecnologia produzidos pelos grandes centros e exportar bens primários, matérias-primas, commodities, num verdadeiro intercâmbio desigual, como bem assinalou Marini (1990).

Nesse sentido, observam-se políticas neoliberais incrementadas por toda a América Latina a partir da década de 1980. Já que a crise do modelo fordista/taylorista de produção e do Welfare State se acentuaram nos países europeus, a reestruturação produtiva por intermédio do toyotismo e o retorno ao liberalismo através de uma nova roupagem (o neoliberalismo) foram reclamados a fim de aliviar as tensões da crise cíclica do capital. Ao mesmo tempo, esta saída para a crisemostra a predominância de um projeto externo para a América Latina, incompatível com o seu projeto de libertação nacional. Reforçando a sua dependência histórica, para Marini (1992), os países latino-americanos estão, ainda hoje, subjugados às intempéries da economia mundial capitalista, porque "A economia exportadora é [...] uma formação social 
baseada no modo capitalista de produção, que acentua até o limite as contradições que lhe são próprias" (MARINI, 1990, não paginado).

Os resultados da transição da economia mundial em etapa superior é, segundo Marini (1992), para a América Latina, uma reconversão econômica que tem como resultados a superexploração do trabalho, a ausência de desenvolvimento dos sistemas de proteção social que vêm, inclusive, sofrendo constantes ataques, com os cortes nas políticas sociais, o fim do protecionismo, a redução do papel do Estado, etc.

A superexploração do trabalho é, inclusive, na tese de Marini (1990), um dos pontos que mais particularizam a dependência na América Latina. Afirmando que ao contrário dos países capitalistas avançados, em que a produção e a circulação de mercadorias estão em relação direta, assiste-se, nos países dependentes, uma condição oposta: uma vez que o consumo de mercadorias não interfere em sua produção, não há preocupação efetiva em garantir a reprodução da força de trabalho, produzindo uma intensificação da exploração do trabalho no continente, ao passo de sua substituição por novos braços sempre que viável e mais produtivo. Ademais, a mais-valia obtida na periferia não é realizada internamente, mas acumulada no centro: o que acontece é, portanto, uma transferência de valor. Nesse sentido, tendo em vista a "incompletude" da realização da mais-valia na própria periferia, é preciso buscar outras vias para a geração de excedente. No contexto dos países dependentes, essa outra via é precisamente a superexploração do trabalho - estratégia da lógica do capital que também auxilia no alívio da tendência da queda da taxa de lucro dos países centrais.

Assim é que, neste contexto, é urgente que a América Latina integre-se na economia mundial, mas não da maneira como está sendo integrada, quer dizer, anexando-se completamente aos países centrais e abrindo suas portas ao capital internacional. É preciso antes que esta integração se efetive a partir de um verdadeiro projeto de libertação nacional que reoriente os países latino-americanos para suas próprias demandas nacionais, atentando para as necessidades de seus trabalhadores/as (MARINI, 1992).

Diante deste lócus caótico que restou à América Latina, historicamente subjugada e em uma condição dependente em relação aos países cêntricos, é possível questionar a entrada na era Moderna: De fato, há e/ou houve uma Modernidade para a América Latina e para os países dependentes? Na medida em que estes se desenvolvem de acordo com as flutuações da economia capitalista mundial e levam a cabo uma superexploração da força de trabalho, somada ao constante aviltamento do sistema de proteção social, é inegável, retomando Dussel (2005), a irracionalidade do Moderno.

Irracional também pelo fato de que a própria sociedade capitalista se funda na contradição, na exploração, na degradação, quer dizer, no desmanche, de tudo o que era sólido, no ar. A dependência e a produção do subdesenvolvimento são, pois, partes constitutivas da dinâmica capitalista em escala global, configurando-se no lado oposto da própria Modernidade. Para a América Latina, por sorte (ou resistência), só pode lhe restar uma única alternativa para o ingresso no Moderno: o desenvolvimento daquele verdadeiro espectro que já ronda sua atmosfera. 
3 AS RELAÇÕES ÉTNICO-RACIAIS NO CAPITALISMO DEPENDENTE: enfrentando a questão

Chegado até aqui e assimilado a particularidade que caracteriza a América Latina no contexto geral da divisão internacional do trabalho, subjugada e submetida historicamente aos países centrais, e, em realidade, muito distante daquilo que se pode considerar por Moderno, cabe identificar como o traço histórico da dependência também trata de assentar as relações étnico-raciais em nossa periferia. Se sob a realidade latino-americana pesa o julgo da dependência e do subdesenvolvimento como um polo oposto necessário da Modernidade trazida pela sociedade capitalista, a chamada questão racial adquire ainda maior complexidade, dadasua necessária interlocução com a dependência.

Como bem indica lanni (2004), a questão racial está estreitamente vinculada à vida social dos indivíduos, pois é na vida social que se produzem os consensos, o jogo de forças, a pactuação daquilo que é tolerável e intolerável, ou seja, "[...] revela, de forma particularmente evidente, nuançada e estridente, como funciona a fábrica da sociedade, compreendendo identidade e alteridade, diversidade e desigualdade, cooperação e hierarquização, dominação e alienação" (IANNI, 2004, p. 21).

A questão racial permanece a ser uma questão da Modernidade, haja vista que continua a se desenvolver com ela e a reiterar preconceitos, discriminações e irracionalismos. Paralanni (2004), o século XXI ainda reproduz as operações de "limpeza étnica" - tal como a oficializada pelo nazismo durante a Segunda Guerra Mundial, expandindo a "civilização ocidental". Isso demarca a permanente tendência em afirmar a superioridade de determinadas civilizações ou povos em detrimento de outros. Em nome da civilização ocidental e de sua expansão é que se atribui ao homem branco, o "fardo" das "[...] técnicas de expansão do capitalismo, visto este como modo de produção e processo civilizatório" (IANNI, 2004, p. 23).

Assim é que pela mesma "lógica ocidental" e europeia, quer dizer, de valorização do homem branco europeu como modelo racial ideal - porqueasua figura também está atrelada à expansão do capitalismo e de suas formas "civilizatórias", em nome do qual ele coloniza (e escraviza) - a questão racial adquire relevo na medida em que a afirmação de um modelo racial ideal implica na existência, de outro lado, de uma multiplicação de xenofobias, preconceitos e segregações de todos aqueles que não participam do modelo racial idealizado (IANNI, 2004).

A partir daí, a pergunta que então poderíamosnos indagar é a seguinte: Quem se encontra no outro lado do polo? Certamente, todos os não-brancos; todos que, na realidade latino-americana, dão o tom de sua particularidade: os indígenas, os negros escravizados, os nativos; as mulheres e crianças abandonadas.

Por esse motivo, lanni (2004) toma que, ao fortalecer e reproduzir as xenofobias, preconceitos e segregações pela adoção de um modelo racial ideal, há uma metamorfose da questão da etnia para a questão da raça. A raça, racialização e/ou racismo, como o autor toma, 


\section{PENSANDO AS RELAÇÕES ÉTNICO-RACIAIS NO CONTEXTO LATINO-AMERICANO DEPENDENTE: uma questão \\ contemporânea para o Serviço Social}

[...] são produzidos na dinâmica das relações sociais, compreendendo as suas implicações políticas, econômicas, culturais. [...] A "raça" não é uma condição biológica como a etnia, mas uma condição social, psicossocial e cultural, criada, reiterada e desenvolvida na trama das relações sociais, envolvendo jogos de forças sociais e progressos de dominação e apropriação. Racionalizar uns e outros, pela classificação e hierarquização, revela-se inclusive uma técnica política, garantindo a articulação sistêmica em que se fundam as estruturas de poder. Racializar ou estigmatizar o "outro" e os "outros" é também politizar as relações cotidianas, recorrentes, em locais de trabalho, estudo e entretenimento; bloqueando relações, possibilidades de participação, inibindo aspirações, mutilando práxis humana, acentuando a alienação de uns e outros, indivíduos e coletividades (IANNI, 2004, p. 23).

Ao contrário da etnia, que valoriza e leva em conta a particularidade biológica constituinte de cada povo, a classificação por raça, racialização e/ou racismo leva a hierarquização dos povos que, nas relações sociais, considera a característica fenotípica como um "estigma" e cria uma determinada conformação cultural que desqualifica, inferioriza e subordina determinadas etnias em relação a outras. Assim é que "[...] na medida em que o indivíduo em causa, podendo ser negro, índio, árabe, judeu, chinês, japonês, hindu, angolano, paraguaio ou porto-riquenho, está em relação com outros, aos poucos é identificado, classificado, hierarquizado, priorizado ou subalternizado" (IANNI, 2004, p. 23).

Fornecendo uma bela análise sobre a formação do povo brasileiro, Darcy Ribeiro (1995) é quem também pode nos auxiliar a pensar a conformação das relações étnico-raciais no Brasil, contribuindo para refletir em "nível" latino-americano. Realizando uma análise da vasta diversidade étnica e cultural que é o povo brasileiro, formado pela miscigenação entre colonizador branco europeu, negro africano e índio nativo, identifica a formação de um povo novo que é, precisamente, o povo brasileiro: este se forma a partir de uma mestiçagem que dá origem a uma identidade nacional própria ao nosso povo.

$\mathrm{Na}$ análise de Ribeiro (1995), a população nativa do país teve seu modo de viver radicalmente modificado pela chegada de um novo protagonista, o europeu colonizador. A subjugação dos índios aos colonizadores brancos europeus se deu por todas as frentes: na disputa pelos territórios e riquezas, na escravização, na mercantilizando das relações de produção e na descaracterização dos costumes e da língua nativa. Para ele, o colonizador branco invadiu o território brasileiro com a sua civilização e não fez senão saquear as riquezas do continente para estruturar um mundo colonial para enriquecer a Europa.

Afora a escravização indígena do início da colonização, a produção açucareira também contou com a sustentação da força de trabalho escrava africana. O negro foi obrigado a se "aportuguesar" na nova terra, ao passo em que sua utilidade estava em sua utilização como "animal de carga". As marcas dessa escravização no Brasil deixam, segundo Ribeiro (1995), a cicatriz do torturador e a brutalidade racista cravada em nossa herança.

Na tese de Ribeiro (1995), construímos nosso próprio povo ao afirmar uma unidade étnicoracial:colonizador branco europeu, negros e índios deram cor ao nosso mosaico e instituíram diversas variedades locais presentes até hoje. É exatamente esta a riqueza de nosso país. O povo brasileiro não é um 
povo arcaico. $O$ atraso está antes no fato de as classes dominantes se submeterem, no âmbito da economia mundial, aos países cêntricos. Elas atuam como fator de atraso porque sacrifica seu povo e o progresso de seu país aos interesses exógenos, isto é, submetem o seu povo a um viver não para si, mas para os outros.

Se a valorização do povo brasileiro e do caldo cultural que forma nossa identidade é ressaltado por Ribeiro (1995), por outro lado, não deixa de assinalar a herança que se perpetua até hoje em nossas relações sociais: o peso do escravismo no país e a adoção de um modelo racial ideal, conformado na figura do branco europeu, produziram aquelas xenofobias, preconceitos e segregações apontadas por lanni (2004). Ainda hoje, no Brasil, o escravismo deixou a marca da discriminação e do preconceito sob os negros. Dissociada da formação social brasileira, a representação social que se faz do negro na sociedade é a associação da negritude com tudo aquilo que existe de negativo e inferior. Ora, ademais das condições de vida e de trabalho durante a escravidão, a libertação dos negros não lhes concedeu condições melhores para reproduzir sua própria existência, já que passavam, agora, a disputar a venda da força de trabalho com os imigrantes europeus. Assim é que a herança deste período é a reprodução de um racismo assimilacionista no Brasil, quer dizer, um racismo ainda mais discriminatório porque aceita que o negro participe da sociedade nacional somente na medida em que ele se "branqueie": o negro, para ser aceito, não pode se constituir como negro, mas deve se identificar como moreno claro, pardo, mulato, etc., estabelecendo uma escala de cores, em que quanto mais "branco", mais cidadão e participante legítimo da sociedade nacional podem vir a ser (RIBEIRO, 1995).

Gorender (2016) é quem também contribui na caracterização do período escravista colonial, reforçando a representação social do negro na sociedade brasileira daquele período. Ser escravo estava relacionado, em primeiro lugar, à característica de ser propriedade de alguém, inserindo-se em uma relação de sujeição a outrem e se configurando como instrumento de trabalho "animado". A relação entre o proprietário e a propriedade era sempre vertical: o proprietário estabelecia o seu domínio sob a propriedade e nunca 0 contrário. Apesar de ser reduzido a coisa e/ou objeto, Gorender também assinala a profunda contradição instalada em seu íntimo: a condição de ser tratado como coisa, mas se constituir como ser. Por isso, como representação social de "coisa", o trabalho e o castigo, para o escravo negro, estavam diretamente relacionados. $O$ trabalho se configurava na objetivação de sua condição de coisa e/ou propriedade e a resistência a ele tornava o castigo natural e, até mesmo, justo (GORENDER, 2016).

São essas marcas deixadas em nosso passado colonial que permanecem a pesar sob as relações étnico-raciais que se estabelecem hoje em nossa região. Ademais, associadas à adoção de um modelo racial ideal, cuja adoração ao branco europeu se perpetua desde o processo de colonização latinoamericana, contribui para enraizar a superioridade do povo branco em detrimento de nosso próprio povo, de tal modo que se produz uma hierarquização dos grupos étnico-raciais. 


\section{PENSANDO AS RELAÇÕES ÉTNICO-RACIAIS NO CONTEXTO LATINO-AMERICANO DEPENDENTE: uma questão contemporânea para o Serviço Social}

Mas o racismo e as relações ético-raciais, afora a sua explicação pelo nosso passado latinoamericano colonial, também se conecta profundamente com o traço histórico de nossa dependência.

Como demonstra Clóvis Moura (1994), o racismo faz parte de uma dominação política e ideológica que é própria do modo de produção capitalista. Ainda que possa se manifestar por meio da superioridade de um grupo étnico-racial sob outro, ele se investe de um caráter mais amplo: é uma ideologia intrínseca ao capital que serve para justificar a dominação de determinadas nações sob outras. É, portanto, uma ideologia de dominação, em que o conteúdo do racismo não é apenas étnico, mas, sobretudo, de dominação.

O racismo como uma ideologia de dominação serve de "arma" e de justificativa para os crimes cometidos em nome de um suposto direito biológico, psicológico e cultural. O próprio sistema colonial e a expansão das metrópoles colonizadoras são precisamente um exemplo desse fato, já que justifica a invasão bárbara e selvagem das áreas colonizadas em função do "benefício" da ocupação e civilização branca (MOURA, 1994)

De acordo com Moura (1994), o racismo moderno nasceu do capitalismo, pois veio para justificar a dominação de uns sob os outros a partir de "argumentos científicos". Se a história da humanidade encontrou, ao longo do tempo, diferentes justificativas para este fenômeno da dominação, quer dizer, as crenças sobrenaturais, a doutrina da seleção natural do mais apto, etc., o que o capitalismo fez foi combinar tais justificativas e doutrinas biológicas naturais, apresentando-as como científica. Por isso, em nome de uma ciência europeia, torna-se legítima a missão de extermínio das populações das áreas ocupadas, em face da superioridade comprovada do processo civilizatório branco. Nesta lógica é que, as nações europeias superiores, souberam muito bem roubar as riquezas das colônias - consideradas bárbaras, atrasadas e selvagens -, influindo-lhes de novas culturas, de costumes, de língua e de religião totalmente diversas, desconsiderando as suas próprias tradições, já que eram vistas como povos "sem cultura e civilização".

A passagem do colonialismo para o imperialismo não alterou a estrutura do racismo. Agora, as metrópoles passam a se voltar para as áreas colonizadas como sendo países incapazes de criar uma população interna que se eleve ao nível dos países desenvolvidos (brancos). Os países dependentes e/ou subdesenvolvidos, por se constituírem de uma população majoritariamente não branca, são vistos - pela escória dos países desenvolvidos - como portadores de uma deficiência congênita, incapazes de se desenvolverem por si mesmos. Por isso, oimperialismo - na verdade, um neocolonialismo -, multiplica as formas de racismo e o moderniza, pois permanece a servir como arma para justificar a dominação, reiterando o domínio das áreas atrasadas pelo argumento científico de incapacidade destas (MOURA, 1994).

Vê-se, portanto, que a questão racial se manifesta, na realidade latino-americana, atravessada por diversas determinações: está marcada pelo passado colonial que escravizou a sua população; pela situação de dependência que estabelece em relação aos países centrais, desenvolvidos e brancos; pela 
ideologia da dominação e da superioridade "científica" que estes julgam possuir, explicando a urgente leva da "civilização" para os países subdesenvolvidos; pela intensificação do racismo por intermédio da superexploração da força de trabalho de nossos povos. Todas estas determinações estão certamente enraizadas nas relações étnico-raciais que contornam a realidade latino-americana e que nela se desenvolvem, assumindo aqui um caráter regressivo, pois a dependência intensifica a questão racial, subjugando os povos não-brancos, submetendo-os à superexploração selvagem do capitalismo.

Se as relações étnico-raciais são construídas socialmente em conformidade com as formas de sociabilidade vivenciadas, como já indicou Octavio lanni (2004), é evidente que as relações sociais típicas da sociedade burguesa produzem o "racismo moderno", seja na classificação hierárquica dos grupos étnicoraciais, seja na escala do desenvolvimento e subdesenvolvimento dos países, isto é, na independência e dependência que lançam as diversas nações na competição desigual da economia mundial e tratam de submeter umas em relação às outras.

Por isso, como em nossa hipótese, já sabendo que a situação de dependência latino-americana intensifica a superexploração da força de trabalho, Devulsky (2016), também contribui ao tomar que o racismo se expressa, inclusive, por intermédio da apropriação de mais-valor sob determinados trabalhadores, de modo que a própria força de trabalho se reveste de uma espécie de roupagem étnica. Isso significa dizer que se 0 capital tem a tendência a se valorizar, contornando as suas crises cíclicas, a exploração dos trabalhadores/as negros dos países dependentes é ainda mais acentuada, visto que a periferia se torna impulso para a acumulação e valorização do capital internacional, isto é, dos países cêntricos.

Somada à roupagem étnica da superexploração da força de trabalho, sobretudo, na periferia dependente, Paiva, Rocha e Carraro (2010) indicam que a ausência de um sistema de proteção social na América Latina intensifica as precárias condições de vida dos povos latino-americanos. Se vimos que, de acordo com Marini, o excedente econômico produzido na periferia é transferido para o centro - levando a uma exploração mais intensiva de mais-valia pelo mecanismo da superexploração do trabalho - o mais-valor obtido de forma extraordinária é, assim, como mostram as autoras (2010), em parte apropriado pela burguesia nacional e, de outra parte, destinado à aquisição de bens industriais produzidos pelos países centrais. Este evidencia que, "simplesmente", não existe investimento efetivo em um sistema de proteção social nos países da América Latina e em políticas sociais. Em nosso continente, esta ausência reforça a intensa exploração dos trabalhadores/as que têm acesso somente a algumas garantias ou direitos sociais em função da árdua luta política das massas.

Assim é que Devulsky (2016) assinala que, a luta antirracista não pode estar desconectada da luta anticapitalista. A luta anticapitalista é indispensável para a luta antirracista. Na medida em que se perde de vista este horizonte, não há uma completa incorporação do negro na sociedade, mas senão, numa sociedade 
de mercado. Esta reflexão é essencial, sobretudo, para a América Latina - uma região em que capitalismo e racismo estabelecem uma relação direta, histórica e, até então, ininterrupta.

\section{CONSIDERAÇÕES FINAIS}

O capitalismo dependente que se reproduz na realidade latino-americana impacta diretamente as relações étnico-raciais que se estabelecem, conformando um caráter regressivo a questão racial. Sem perder de vista a particularidade da América Latina, isto é, o traço histórico da dependência que se impregna nas relações sociais da periferia, buscamos traçar uma reflexão com a finalidade de captar as determinações que nos distingue.

Para tanto, reafirmamos que, situados em uma posição periférica na divisão internacional do trabalho e submetidos a uma intensa superexploração da força de trabalho, a questão do enfrentamento ao racismo só se torna verdadeiramente revolucionária e com possibilidades de superação na medida em que atingir a raiz da produção de tais relações étnico-raciais, quer dizer, transmutar-se para a verdadeira luta anticapitalista.

Nesse sentido é que, o movimento negro periférico e também o movimento dos trabalhadores em geral têm o desafio de não esgotar suas reivindicações dentro do âmbito da legalidade burguesa, mas articular-se com a luta anticapitalista, numa verdadeira renovação da luta dos trabalhadores/as, que é revolucionária porque se imbrica com o racismo e também com o sexismo.

Nessa perspectiva, a questão racial se coloca como uma questão contemporânea para o Serviço Social, porque é um princípio ético-político de luta pela eliminação de qualquer forma de dominação e exploração de classe, etnia e gênero. Como profissão que se construiu e se maturou historicamente na defesa da construção de uma nova ordem social, que permita o pleno desenvolvimento em direção às capacidades humano-genéricas, particularizar desde um prisma latino-americano a questão racial, é também fornecer instrumentos mais precisos de análise em torno de uma das faces das expressões da "questão social". Munidos do devido rigor teórico-metodológico, a intervenção profissional tem condições de desvelar real, particularizar a questão racial na região e investir-se da luta antirracista, porque antes, anticapitalista.

\section{REFERÊNCIAS}

DEVULSKY, Alessandra. Estado Racismo e Materialismo. In:Revista Margem Esquerda. n. 27, São Paulo, Boitempo Editorial, out., 2016, p. 25-30.

DUSSEL, Henrique. Europa, Modernidade e Eurocentrismo, In: LANDER, Edgardo (org.) A Colonialidade do Saber:Eurocentrismo e Ciências Sociais, Buenos Aires: CLACSO, 2005, p. 25-34. 
FERNANDES, Florestan. Sociedade de classes e desenvolvimento.5. ed. rev. São Paulo: Global, 2008. GORENDER, Jacob. O escravismo colonial. São Paulo: Expressão Popular; Perseu Abramo, 2016.

IANNI, Octavio. Dialética das relações raciais. In: Estudos avançados. v.18, n.50, São Paulo, jan./abr., 2004, p. 21-30.

MARINI, Ruy Mauro. América Latina: dependência e integração. São Paulo: Editora Página Aberta, 1992.

MARINI, Ruy Mauro. Dialética da dependência. 10. ed. Tradução: Marcelo Carcanholo, Universidade Federal de Uberlândia - MG. Post-scriptum traduzido por Carlos Eduardo Martins, Universidade Estácio de Sá, Rio de Janeiro, RJ. México: Editora Era, 1990.

MOURA, Clóvis. O racismo como arma ideológica de dominação.1994. Disponível em http://marxismo21.org/clovis-moura-marxismo-e-questao-racial. Acesso em: 13 jan. 2021.

PAIVA, Beatriz; ROCHA, Mirella; CARRARO, Dilceane. Política Social na América Latina: ensaio de interpretação a partir da Teoria Marxista da Dependência. Ser Social (UnB), v. 12, 2010, p. 147-175.

RIBEIRO, Darcy. 0 povo brasileiro: a formação e o sentido do Brasil. São Paulo: Companhia das Letras, 1995. 